\title{
Portraits That Matter
}

King Chulalongkorn Objects and the Sacred World of Thai-ness

Irene Stengs

Researchers such as Birgit Meyer, David Morgan, and Christopher Pinney have argued that sacred portraits belong to a specific category of religious objects. ${ }^{1}$ The most important difference between them and other religious images is that they are not just something to be looked at, but possess a gaze of their own. This gives them a particular potency in shaping and sustaining the "given world" of their beholders. Explaining the ontological status of a picture as the concrete, materialized manifestation of an image, W. J. T. Mitchell argues that images are not separately existing immaterial entities like a Platonic Ideal but more like an Aristotelian species, of which a picture is a material specimen. ${ }^{2} \mathrm{~A}$ portrait is thus not a passive reminder of the absent being it depicts; it is, in some way as yet to be determined, an instance of that being, at once material and spiritual, with its own distinct and material history. Mitchell's argument limns a perspective that can allow us to avoid the problematic Platonic and classical Western opposition between material and spiritual worlds, and it sheds light on the surprising ways that in other cultures even the most mundane material objects may exert spiritual power over people. ${ }^{3}$ In this chapter, I will explore these insights by examining portraits of the Siamese king Chulalongkorn (Rama V, r. 1868-1910), particularly in light of the deified person he became, as material carriers of a cult that marked the world of the urban Thai middle class in the $1990 \mathrm{~s}^{4}$

In the late 1980s, almost eighty years after his death, King Chulalongkorn became the object of a nation-wide personality cult. The development of the cult should be understood against the background of increasing hopes and anxieties about Thailand and Thai identity in a globalizing world. In that respect, the King Chulalongkorn cult can be regarded as one of the many new religious movements that emerged worldwide as a reaction to the booming neo-capitalist 1990s. ${ }^{5}$ 
To understand why King Chulalongkorn became an object of worship, one must study how he is remembered and how this memory is shaped. On the level of the individual worshipper, the "remembrance of King Chulalongkorn" does not refer to people's personal memories of someone they have known but is "transferred knowledge": 6 although they have never met the king in person, people know who he was, what his achievements and qualities were, and why this makes him a significant figure in their personal, day-to-day lives. A vast corpus of King Chulalongkorn stories circulates through schoolbooks, popular magazines, and radio and television broadcasts. In these stories, several major narratives can be distinguished, each depicting the king in one of his particular capacities. I call these narratives "narrated portraits." The narrated portraits show which aspects of the king's life and personality are so significant for the Thai that the king is generally referred to as the Great Beloved King (somdet phra piya maharat, an epithet given him in 1908, on the occasion of the fortieth anniversary of his accession to the throne). As with material portraits, narrated portraits are particular concretizations of an image, textual concretizations, that make the Great Beloved King a part of the world that his worshippers can experience.

The core of what we may call the myth of King Chulalongkorn can be summarized in four narrated portraits. "King Chulalongkorn used to visit the countryside" depicts King Chulalongkorn as a king with such a sincere interest in the needs of his subjects that he traveled the countryside incognito to become involved with them in person. " "King Chulalongkorn abolished slavery" tells how the king furthered the well-being of his subjects, ended feudal arbitrariness, and introduced modern individuality. "King Chulalongkorn saved Thailand from becoming a colony" narrates how the king's diplomatic insights and skills maintained the independence of Siam (Thailand) in the era of colonization, the only country in Southeast Asia to manage to do so. The fourth portrait depicts King Chulalongkorn as the kingdom's “Great Modernizer." During the king's reign, a wide variety of typically nineteenth-century modernizations were introduced (railways, electricity, waterworks, and the like), which generally are presented as personal achievements of King Chulalongkorn. Moreover, the king's genius was to be able to select the good that the West had to offer for the benefit of his subjects, while protecting them from the bad.

The worship for King Chulalongkorn takes place in a world saturated with canonical and noncanonical Thai Theravada Buddhist concepts of kingship and the supernatural qualities of Buddhist kings. Buddhist kings are considered to be men with merit and grace, who emanate a benevolent power (bun barami) that all the king's subjects throughout his kingdom can experience. Deceased kings continue to protect the kingdom as guardian angels. ${ }^{8}$ However, not all Siamese or Thai kings have become the object of a cult. The steep rise of King Chulalongkorn's popularity in the 1990s reflects, rather, the appeal of core elements of his biography in the light of the specific social and economic circumstances of the time. 
We may seek to understand the appeal of the Great Beloved King from the narratives, but the vigor of this appeal is immediately apparent from its material manifestation: the omnipresence of King Chulalongkorn portraits. At the time of my research, from 1996 through 1998, the king's portraits were found all over the country, particularly in urban areas. Offices, restaurants, shops, private homes, temples, spirit shrines, railway stations, and other public buildings - there were almost no places without a portrait or statuette of the king. The source of the wide variety of available paintings, photographs, and statues was King Chulalongkorn himself. From the outset of his reign, the king showed a great interest in portraiture and photography, and he had himself depicted using numerous techniques. ${ }^{9}$

The early portraits of King Chulalongkorn and his family were primarily intended to decorate his palaces. Portraits were also sent to European courts as gifts, following a European custom adopted during the Fourth Reign, the reign of King Monkut (Rama IV, r. 1851-68). For the general populace, the abstract image of King Chulalongkorn as "king of Siam" literally got a face in the final decades of the Fifth Reign. On coins and stamps, portraits of the king found their way throughout the kingdom. In addition, these portraits appeared on picture postcards and New Year's greeting cards and were reproduced for widespread distribution, at least in urban and elite environments. There they became objects of worship. In the words of a contemporary observer, Quaritch H. G. Wales:

One more method of paying homage to deceased kings in Siam remains to be mentioned: the setting of a photograph or lithograph of the particular king on a table, before which are made the usual offering of lighted candles, flowers, and incense. This is now a very popular custom, both in government institutions and private houses, since every Siamese home possesses at least a cheap lithograph and can thus show its loyalty in this easy and practical manner. ${ }^{10}$

As the mass production of portraits began only during the reign of King Chulalongkorn, Wales must be referring to portraits of King Chulalongkorn and his son King Vajiravudh (r. 1910-25), the only deceased kings whose portraits were available. The passage demonstrates that the worshipping of royal portraits—although rather new at the time-predates the development of the King Chulalongkorn cult. At the same time, this passage highlights the power of the alliance between new media, commerce, and religion from the outset. This alliance, therefore, cannot be understood as specific to our time.

The practices for worshipping King Chulalongkorn draw upon popular ideas about the powers of sacred images, a fundamental dimension for understanding the mass production of the king's portrait. Elsewhere I have elaborated on the specific capacities of King Chulalongkorn portraits as, to paraphrase Meyer, objectifications mediating religious experience. ${ }^{11}$ Thai people may experience their special relationship with King Chulalongkorn through a portrait of the king-a context-specific encounter with the sublime. ${ }^{12}$ 
Here I want to highlight the agency of the objects themselves, so as to give insight into how King Chulalongkorn portraits tend to steer their own production, distribution, sustenance, and display. I therefore will take the agency of these objects, their power to affect the world and their significance in the creation of people's life world, as my specific focus.

\section{Moving Objects}

King Chulalongkorn portraits have the capacity to transform their environment by radiating their sacredness. The daily practice of the King Chulalongkorn cult consists, therefore, in concrete dealings with things in the world rather than merely spiritual actions. Take the case of Bun, a King Chulalongkorn devotee. His practice demonstrates how his dealings with King Chulalongkorn objects transform his personal world into a sacred space.

Bun is the owner of a well-known flower shop in Chiang Mai, the capital city of Northern Thailand. His small shop-which he runs with his sister-is famous for the quality of its flowers, as well as its flower decorations and garlands. Chiang Mai's elite order their flowers from Bun, particularly on occasions of a formal, "national" character, such as a visit of the queen to Chiang Mai or Chulalongkorn Day. ${ }^{13}$ Bun himself is strongly devoted to King Chulalongkorn. This is partly expressed in the eight portraits of the king decorating his shop and its private upper floor. Most of these portraits were presented as gifts to commemorate various occasions, including the opening of the present shop, Bun's birthday, and the New Year. Furthermore, Bun owns a King Chulalongkorn portrait book entitled Best of the Best: The Great Collection of King Rama V (Pramuan Phraboromchai Lakson)..$^{14}$

But Bun's most precious King Chulalongkorn portrait is not on display: it is an original Fifth Reign coin, which he carries always on his body underneath his clothes. An aunt gave him the coin around 1990, in the "knowledge" that he would be the right person to own it. Since then, Bun has taken great efforts to make the coin into a precious medallion (lokket). ${ }^{15}$ It is encased in elaborately worked gold, and its chain is also made of heavy gold. A small ruby decorates the medallion's top; two rows of small diamonds (brought back from a holiday in Belgium) are inlaid the left side; and an emerald completes the setting below. The process of embellishing the medallion has been executed bit by bit. Every time Bun has some money or comes across a nice stone, he adds to his design. ${ }^{16}$ In its state in 1997, the lokket would have cost about a hundred thousand baht. But Bun, of course, has no intention of selling this unique medallion.

Bun owns several other King Chulalongkorn coins and medallions. These objects, however, were newly produced on the occasions of commemorative events or for charities. Occasionally, he buys them from organizations or vendors. In 1996, Bun purchased ten such medallions at prices ranging between one and two thousand baht. Four of the medallions he kept for himself; the other six were gifts. Thus, Bun owns a wide array of 
King Chulalongkorn portraits and objects. His desire for portraits, however, never seems to be entirely satisfied. Once he told me that there is one particular King Chulalongkorn portrait he would really like to add to his collection: a good photograph of the equestrian statue. As Bun explained, there is a fundamental difference between the statue and other portraits: the equestrian statue is a portrait of the king as royal Buddha (phra phuttha chao luang), ${ }^{17}$ whereas the other portraits depict him as royal father (sadet pho). The equestrian statue is the "highest" portrait of King Chulalongkorn, because it was erected on the occasion of his fortieth year on the throne; no other king in Thai history had ever ruled so long. This portrait therefore depicts King Chulalongkorn at the peak of his import and power. ${ }^{18}$ Apparently, the many widely circulating and easily available photographs of the equestrian statue were not good enough to suit Bun's taste: in his imagination the photograph had to be rare or otherwise impressive.

Bun's story reveals some of the ways in which King Chulalongkorn objects tend to move. First of all, King Chulalongkorn portraits often move as gifts. A portrait is always an apt present for someone who is known to seek special refuge with King Chulalongkorn, and a King Chulalongkorn worshipper presents himself as such to the world by displaying one or more King Chulalongkorn portraits. Consequently, many restaurants, shops, offices, and other semi-public and private spaces are colored by King Chulalongkorn portraits. The body may also serve to show an individual's veneration for the king: although Bun wears his lokket under his clothes, most lokket owners-women in particular-wear these adornments in plain view, moving them wherever they go. ${ }^{19}$ The lokket are at once material testimonies to their owners' adherence to the king, and testimonies to their taste and wealth. ${ }^{20}$ The presence of a single portrait may attract many other portraits to arrive around it—on birthdays, shop openings, or other auspicious occasions. Waiting in department stores, religious shops, temple shops, jewelry shops, specialized portrait shops, book stores, and amulet markets, as well as food and household-utensil markets, King Chulalongkorn portraits are for sale in great numbers, with the cheapest items (stickers) costing no more than five baht. ${ }^{21}$

Second, King Chulalongkorn portraits move through door-to-door vending charities and small entrepreneurs. Some of the objects obtained may stay; others may continue their travels as gifts. Sombun, who, together with his wife, runs an architecture and contracting firm in Chiang Mai, obtained his first King Chulalongkorn portrait-a plaster replica of the equestrian statue-from a door-to-door vendor at his office in 1991. Although he said he had not been a King Chulalongkorn worshipper, thinking that King Chulalongkorn "was for the desperate" only, he could not refuse to buy the statuette, "because the vendor was willing to make the price very low." The presence of the statuette changed Sombun's life: he gave the object a respectful place in his office, where he eventually made an altar. Thereupon, their then poorly functioning business improved and began to thrive. 
The arrival of the statuette changed Sombun and his wife not only into King Chulalongkorn worshippers but also into disseminators of King Chulalongkorn portraits. In subsequent years, they sent King Chulalongkorn New Year's greeting cards to their friends, relatives, and business acquaintances, sending a different portrait every year. According to Sombun, sending as well as receiving King Chulalongkorn cards is auspicious, which is why it is so important for him to send out these cards.22

Third, King Chulalongkorn portraits may seek out their owners themselves. Although Bun's coin was a gift from his aunt, it could not have been given to just anybody: the object was meant to be given to him. The same element of destiny is present in Sombun's account of the statuette: why, otherwise, would the vendor have made its price so exceptionally low? A parallel story was shared with me by Nui, a restaurant owner in Chiang Mai, who had been searching for an original King Chulalongkorn coin. He could not afford to buy one, however, as such coins are relatively scarce and therefore expensive. One day an amulet vendor came to his restaurant. The man offered him a one-baht coin for fifteen hundred baht, which was still too expensive for Nui. The vendor rejected Nui's counteroffer of five hundred baht and left the restaurant. Thereupon, Nui turned to King Chulalongkorn for help, at the King Chulalongkorn altar in his restaurant. A fortnight later the vendor returned to sell the coin for a mere five hundred baht. After several years, the vendor returned to ask Nui if he could buy the coin back, offering forty thousand baht, which Nui refused, of course.

Renu's first King Chulalongkorn portrait came to her in the form of a crumpled piece of paper that followed her, steered by the wind, until she could not resist picking it up to see what it was: it turned out to be a portrait of the king, dressed in purple. She ironed the portrait, framed it, and gave it a place in her family's restaurant-and the very next day the king saved her brother from a robber who held him at gunpoint. Her brother saw the king knock the gun out of the robber's hand from the portrait.

The idea of special relationships between specific King Chulalongkorn objects and individual people is widely shared, and it is a recurring theme in people's accounts of experiences with King Chulalongkorn. Importantly, it is the objects that take the initiative in establishing these relationships. As agents, they select their owners (Bun, Sombun), come when they know they are welcome or longed for (Nui), or arrive when help will be needed (Renu), exhibiting social qualities similar to human agents. ${ }^{23}$ They assist their owners in constructing their life worlds by providing them with security, economic support, and aesthetic pleasure. In their turn, only through finding their owners can King Chulalongkorn portraits receive the care they "want": ${ }^{24}$ an appropriate place, beautification, and reverence. More concretely, King Chulalongkorn portraits, like all sacred objects, "desire" a "high" place, possibly an altar, with incense and candles. In addition, they want pink roses, a glass of brandy, a cigar, apples, young coconut, and traditional Thai sweets, all favorites of the king. ${ }^{25}$ 


\section{Center of the Cult, Center of the Nation}

The equestrian statue in Bangkok is the central portrait in the King Chulalongkorn cult. Since the first King Chulalongkorn Day (October 23, 1912), the statue has been the focus of the celebration that takes place there. Its core is the national wreath-laying ceremony; representatives and employees of national institutions, semi-governmental organizations, the city, the army, scouts, hospitals, schools, banks, and enterprises all present a memorial wreath (phuangmala) at the equestrian statue. When presenting their wreath, members of each group kneel down together, bow deeply (krap), and salute the king three times (thawai bangkhom). Chulalongkorn wreaths are a category of their own, different from both Western memorial wreaths and regular Thai funeral wreaths. Most designs combine a selection of symbols referring to the king and his particularities (royal attributes, symbols of his deeds, roses), with symbols referring to the organization or institution presenting the wreath. The central feature of most wreaths, however, is a portrait of the king. By the end of the ceremony, the equestrian portrait is surrounded by hundreds of King Chulalongkorn portraits, each lavishly embellished with its own specific details. The exhibition reconfirms the general perception that the modern Thai nation-state owes its very

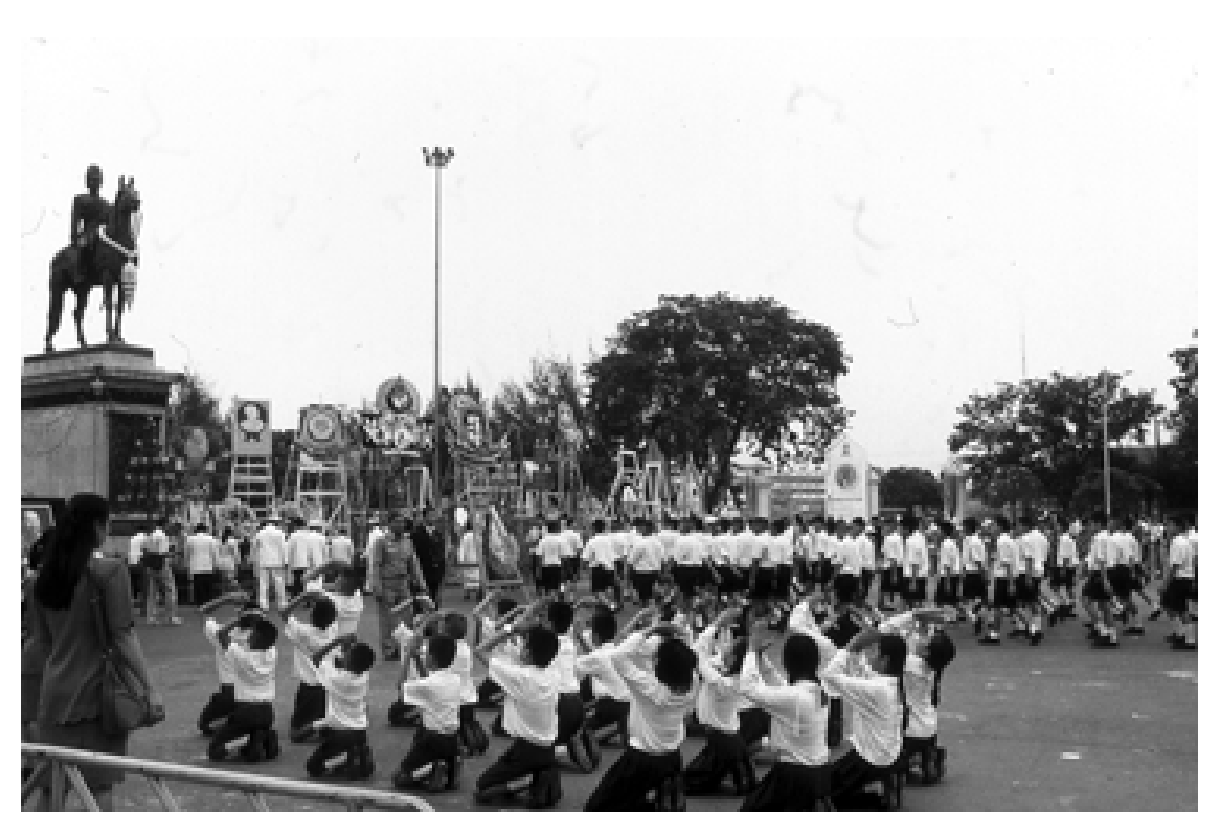

F I G URE 9 Chulalongkorn Day 1996: Schoolchildren kneeling, bowing, and saluting when presenting their school's memorial wreath in honor of King Chulalongkorn at the equestrian statue in Bangkok. 
existence to King Chulalongkorn and that, by implication, all the institutions included do as well.

The early 1990s saw a new, unofficial development, however: people began to gather at the statue to approach the king for support in all kinds of personal desires and anxieties. Combining in a single instance both the founding father of the modern Thai secular nation and a meritorious Buddhist king caring for each of his subjects, King Chulalongkorn is a sufficiently ambiguous figure that almost anybody can seek refuge with him. Tuesday evenings became the most significant moments at the statue, as, reputedly, the spirit of the king descends from heaven into the statue on those evenings around 10 P.M. (Tuesdays are auspicious because King Chulalongkorn was born on a Tuesday.) Although any King Chulalongkorn portrait at any time is a divine presence, on Tuesday evenings the equestrian statue is the king. The immediate presence of King Chulalongkorn through the equestrian statue both promises the certainty of a caring agency and immediately appeals to ideas and emotions surrounding Thai-ness, of which the king has become the epitome.

The equestrian statue attracts both worshippers and other King Chulalongkorn portraits. In the late 1990s, when the cult was at its high point, on an average Tuesday evening the statue offered an impressive spectacle. In the candlelit dark, portraits of the king in the thousands gazed back at the onlooker: the part of the square in front of the statue was

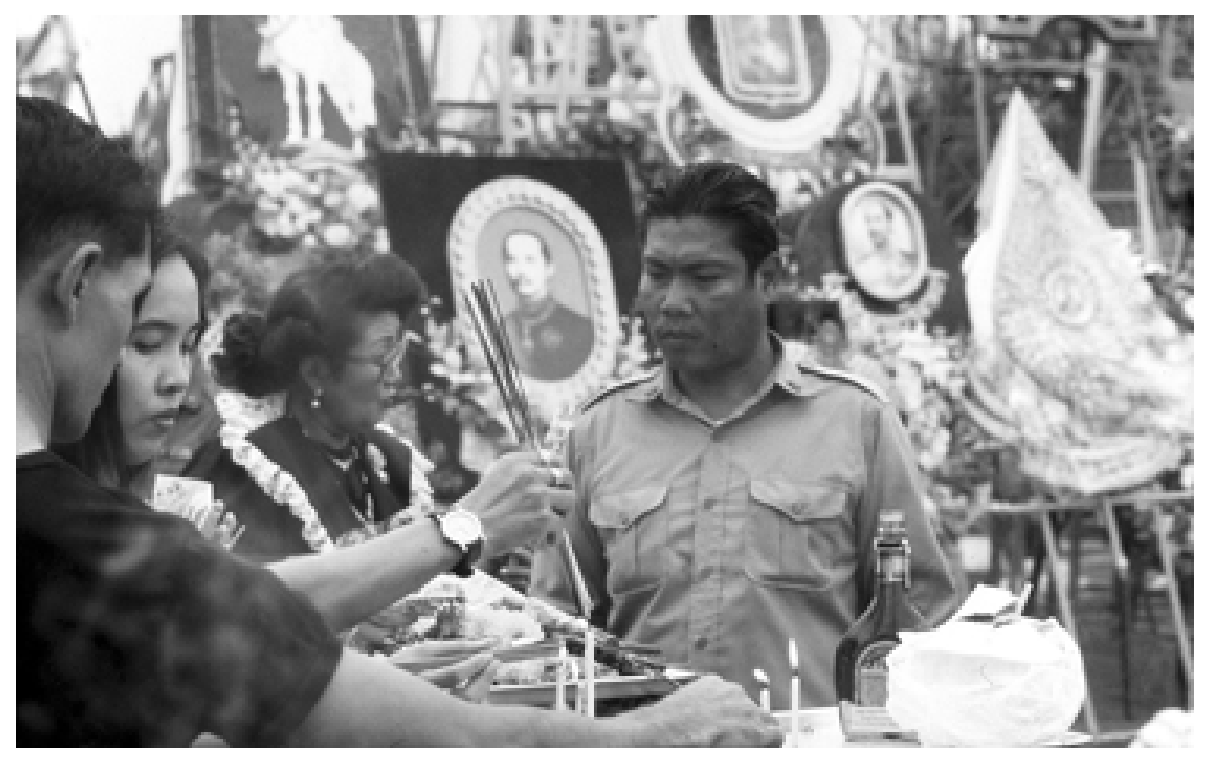

F I G U RE 10 Chulalongkorn Day 1996: After the wreath laying ceremony is over, worshippers come forward to present offerings to the king at the equestrian statue in Bangkok. 
full of King Chulalongkorn portraits placed on low tables and boxes. They were part of many make-shift altars, surrounded by fruits, sweets, brandy, flowers, incense, and candles. Behind the altars small groups of people were seated on mats-families or groups of friends or colleagues_chanting auspicious formulas (khatha), meditating, or chatting. Reputedly, the benevolent power (bun barami) radiating from the statue has the capacity to charge everything in its vicinity, people and portraits alike. Yet apparently King Chulalongkorn portraits have a better capacity to store this power. ${ }^{26}$ Hence, King Chulalongkorn portraits may be "recharged" regularly at the statue, to continue their positive impact on their owners with renewed force.

As an auspicious object, influencing its entire environment, the equestrian statue has also become an important portrait-selling point: in this respect the statue is also a source of auspicious objects. Generally, quite a few pickup trucks are parked next to the statue on Tuesday evenings. Packed with King Chulalongkorn posters, statuettes, and lockets, they serve as moving shops, and many of those portraits find their eventual owners here. Later, depending on their owners' views, they may return to the statue to experience its benevolent power once again.

Thus, the equestrian statue, located in the center of Bangkok, the kingdom's capital city, draws King Chulalongkorn worshippers and portraits into that center, then propels them out again. The statue, therefore, is not just a powerful portrait (a material manifestation) of King Chulalongkorn but also a material center of Thai-ness. Since the idea of Thai-ness virtually coincides with that of the Thai nation, of which the king forms the apex, the statue is thus the material center of the nation. Although the ancient idea that the king is the apex of society has for centuries been a generally shared image, the statue offers for the first time a concrete, approachable picture of that center. Yet it was not planned as the center of the nation, that is, as an objectification of a preexisting idea of such a center. ${ }^{27}$ Rather, the situation should be understood from a performative perspective: once the material statue had been created, charged with its new meaning, it made the center come into existence. ${ }^{28}$

\section{From Vision to Portrait}

A vital part of my research was carried to trace the routes of King Chulalongkorn portraits. Where had they come from? How had they ended up in people's houses and shops? In Chiang Mai, many of the King Chulalongkorn portraits in shops appeared to come from a single temple, named Wat Doi Chang. ${ }^{29}$ This temple, located at the outskirts of the city, turned out to be a true King Chulalongkorn cult center. A life-size golden King Chulalongkorn statue, housed in a special building, distinguished the temple from other temples; normally, temples do not have King Chulalongkorn statues. ${ }^{30}$ The reasons why the statue was created can shed light on the complex interrelationship between the image 


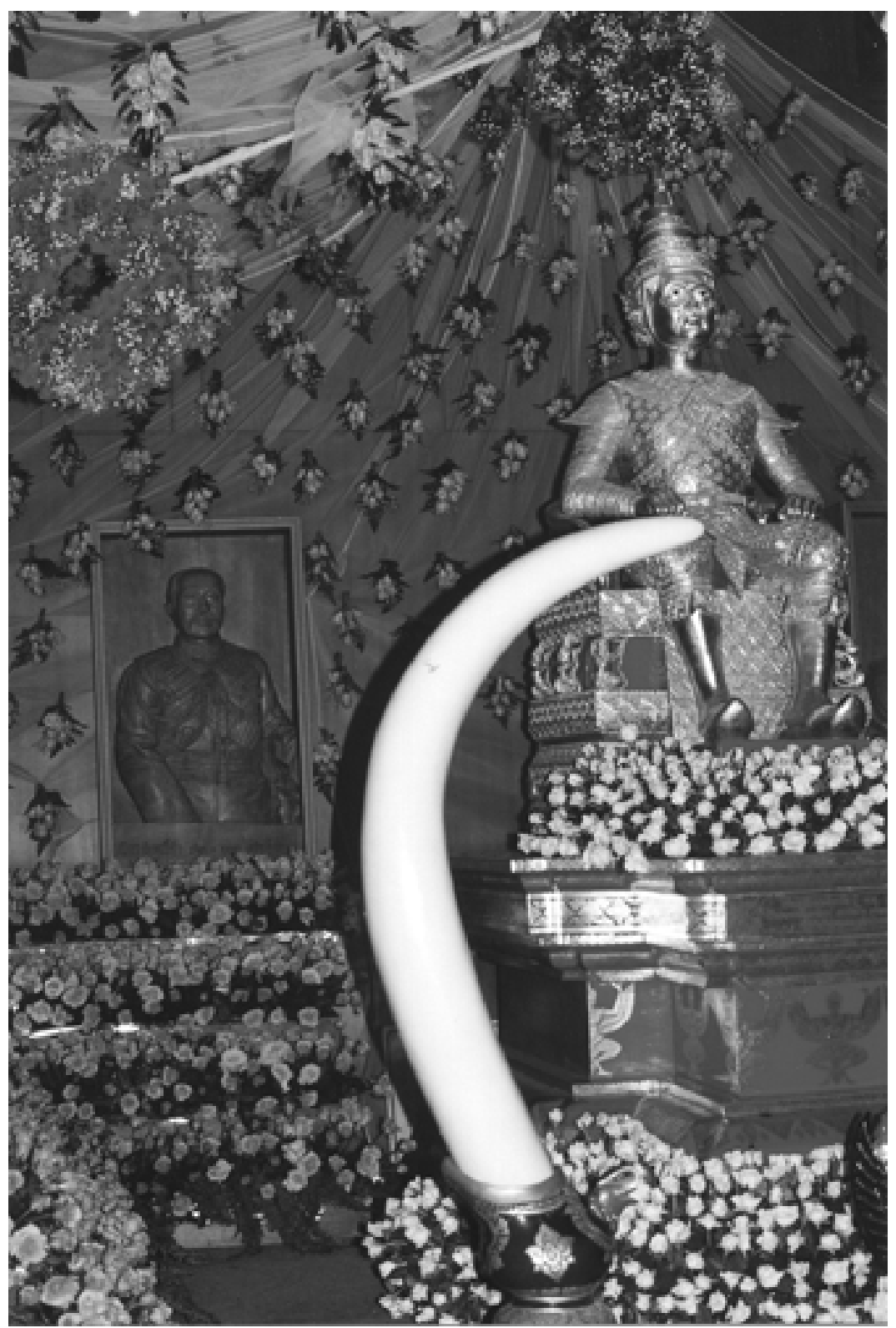

F I G U RE 11 Chulalongkorn Day 1998: The golden statue at Wat Doi Chang, for the occasion decorated with white and red roses, reputedly the king's favorite flower. 
of the deified king, Thai individuals, and King Chulalongkorn portraits. Here is its story, as told to me by the temple's abbot.

One night in 1992, the abbot had a magnificent vision: King Chulalongkorn, in golden attire, with a golden crown, seated on a golden throne, spoke to him. He told the abbot to create a statue identical to the vision. After the vision, the abbot searched photo books on the life of King Chulalongkorn, to-as he expressed it- "see what I have seen." It turned out to be the king during his "second coronation," as depicted in a specific photograph. In addition to charging the abbot with the erection of the statue, the king had also instructed him to start a relief center and school for orphan boys from hill-tribe villages. The combined project-the intended statue and the orphanage-attracted people to the temple. Yet people also came because it became known that King Chulalongkorn often spoke in person through the abbot. Because Wat Doi Chang was a quiet temple, an increased number of (preferably well-to-do) temple visitors was required to finance the construction of the statue and the orphanage. Within a year, sufficient funds were raised. The statue was made and placed in a temple building (wihan) specifically built for the purpose. The abbot insisted that the statue be carved of out of a solid trunk of teak, making it, at that time, unique in all of Thailand.

Importantly, it was the king — not the abbot—who took the initiative in the creation of the statue. This made the initiative a necessity, and auspicious by nature. Second, the king gave detailed visual instructions concerning the eventual appearance of the statue. Hence, like any portrait or photograph created directly after the person portrayed, the statue would truly depict the king and therefore be an "original" portrait, not a mere copy. Third, an existing portrait-the second-coronation photograph; more precisely, a reproduction of that picture-offered material guidance for the making of the statue. Yet again, because not the picture but the vision served as the source of inspiration, the statue is not a copy but an original.

Basically, the account of the creation of the statue is at odds with Western commonsense views. However, for the Thai audience the story follows a familiar idiom (a "recognizable form"), ${ }^{31}$ namely, that of a person experiencing the call of a spirit to become its medium and searching for the meaning of an unfamiliar experience or illness. ${ }^{32}$ This, however, does not imply that the abbot is a spirit medium. In official Buddhism, belief in spirit mediumship is regarded as superstition and hence the rules of the monastic sangha (the community of monks and the official Thai religious institution) forbid monks' acting as spirit mediums or practicing other forms of "magic." In addition, an inherent obstacle to a monk's acting as a spirit medium would be that monks vow to wear only robes; an important aspect of Thai spirit-medium possession is changing dress to prepare to receive a spirit. The audiences identify the various possessing spirits that may come by how the medium is dressed during the ceremony. If a medium is not dressed in accordance with the expected attire of a particular spirit, the medium is either not possessed or is possessed by a different spirit. It is in part the same process that makes a monk a monk: a primary 
differentiating feature between a monk and a layman is the robe. Only in a robe is a man a monk. By implication, a monk can never act as a spirit medium, as that would imply that he literally disrobes.

How, then, are we to understand the relationship between the abbot and the king? Rather than being an instance of spirit mediumship, the link between the two can tell us something about the relationships between persons, images, and portraits, relationships that are fluid and constantly in flux.

\section{A Living Portrait}

Jill, a Thai woman living not far from my house, whom I used to visit, asked me one day if I had ever been to Wat Doi Chang. When I answered in the affirmative, she said, "He looks just like him, and like a real womanizer (chao chu), too, don't you think?" I had no idea whom she was talking about. "The abbot," said Jill. "The abbot, a womanizer?" Upon seeing my amazement, Jill explained, "Yes, just like King Chulalongkorn. The abbot is exactly the king. And look at his eyes. Womanizers always have those wrinkles around their eyes. He is very attractive."

The next day I went to the temple to see for myself. Did the abbot really look like the king? ${ }^{33}$ When I arrived at the temple, the abbot was in the wihan, receiving people who had come to consult him and present offerings to the temple. I stayed for almost two hours, continuously observing him, but I was not yet convinced. Then the abbot turned his head to the left, assuming the same pose as the king in a photograph placed behind him. This photograph had been taken during one of the king's visits to Europe. The king, dressed in a Western suit and hat, looks more like an Italian movie star than a Thai king, and certainly nothing in the picture would remind one of a Buddhist abbot. Yet at that moment I saw the resemblance, and I realized that the photograph could not have been placed behind the abbot by coincidence. Whether the abbot was in the wihan or in the sala (the temple's main building), the photograph was always placed behind him. ${ }^{34} \mathrm{On}$ another occasion, confirming the abbot's resemblance to the king-and his awareness of the fact-a woman presented him with a small, cross-stitched copy of another portrait, portraying the king's face from the same angle as the Italian portrait. The abbot, with clear appreciation, immediately placed the new portrait next to the other one; it remained there throughout my fieldwork period.

The abbot's physical resemblance to the king helped to circumvent the limitations that being a monk imposes on embodying an entity from the spirit world. The abbot himself, as it were, had become a living portrait of the king-or, in Mitchell's terms, a particular concretization of the image of King Chulalongkorn. However, irrespective of the abbot's particular features, he could not but derive his resemblance from another specific portrait. From this we can conclude that the conflation "king," "abbot," and 


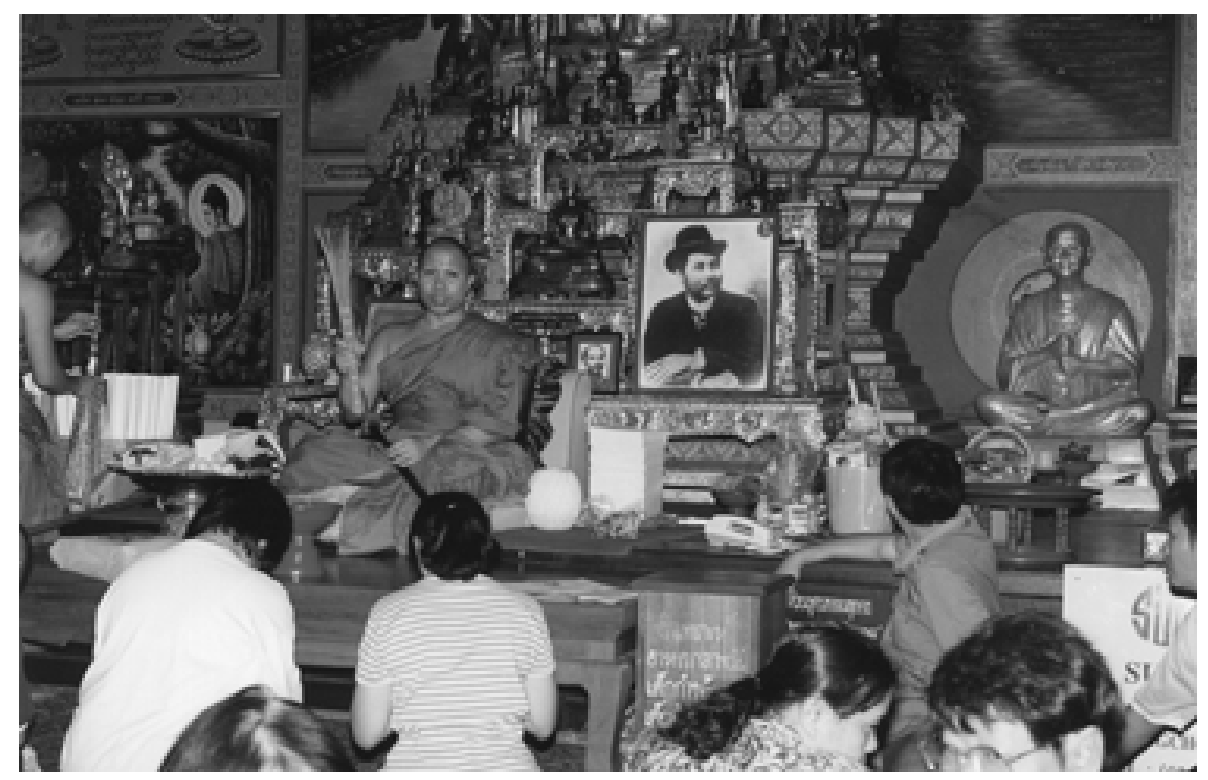

F I G U R E 12 A "living portrait" of King Chulalongkorn: The abbot of Wat Doi Chang. At right are two portraits of King Chulalongkorn, which highlight their physical resemblance.

"portrait" is unstable and in constant need of reconfirmation by a beholder. The abbot is not always the king's living portrait, and not for everybody. Such conflations therefore are momentary and remain largely implicit.

\section{The Golden Statue, the Abbot, and the King}

In this final section, I will compare the roles of the statue and the abbot as movers of people and objects, then return to the issue of the relationship between image and picture, narrowed down to the specific relation between image and portrait.

The temple became a center dedicated to King Chulalongkorn after the king's image found concretization in two extraordinary portraits: the golden statue and the abbot. What, exactly, did that process entail? Without, in Webb Keane's words, exteriorization in a recognizable form, the vision would have remained an "idiosyncratic experience" in the abbot's head. ${ }^{35}$ The narration of the vision was a first exteriorization: its idiom can be recognized as belonging to the domain of Thai spirit mediumship. The second exteriorization was the vision's materialization in the recognition of the famous coronation picture as the image of the statue-to-be. The constitution of the abbot as a living portrait 
was the third step in this process, materializing the vision of the king's image in a manner that others could see, hear, and approach.

Does this imply that it would be impossible, finally, to distinguish between the king, the statue, and the abbot? In the sala, several portrait compilations visualize the spiritual link between the king, the statue and the abbot-for instance, a portrait of the king at the top, the highest position, with a picture of the (unfinished, not yet gilded) statue in the middle, and lowest — but at the same time most at the fore, and most visible — the abbot. These compositions confirm the conflation. At the same time, however, the different forms in which the image materializes (vision, narrative, statue, face) matter: they have different effects in the world.

The narrative attracted people to the temple and raised donations so that the statue could be realized. Once the statue had been created, it attracted visitors to the temple. It began to take on a life of its own, and new relationships between the statue, devotees, and other King Chulalongkorn portraits started to develop. The statue was worshipped, embellished, and copied, ${ }^{36}$ and it attracted many other portraits. Its presence also triggered the carving of other King Chulalongkorn portraits out of wood. These portraits, each carved out of a single block of wood of exceptional size, were commissioned and donated with the specific objective of being placed on a ledge next to the original statue. In consequence, the statute is surrounded by fifteen King Chulalongkorn portraits over one meter tall, which leave no space for the many, many other portraits that have been donated. The abbot complained, one day, that he did not know where to keep all the portraits. The other portraits were initially put on display in the sala. The continuous arrival of new portraits eventually led to the construction of a new room, especially designed to store them.

The process of concretizing the statue and its ensuing life made the temple a King Chulalongkorn cult center. The temple, itself a material and visual manifestation of the presence of the image of King Chulalongkorn, allowed the abbot to develop a power of his own, and gradually he performed his spiritual services more and more independently of the golden statue and further away from its immediate vicinity. The portrait compilations mentioned above can also be read as visualization of this process: King Chulalongkorn's image moves into the background, while the person of the abbot is at the fore as the temple's most prominent attraction, as if having absorbed the king's charisma. 